\title{
Analysis of drillhole deviation during drawbell construction in block caving
}

\author{
N Bustos W A School of Mines, Curtin University, Mining 3, Australia \\ E Villaescusa W A School of Mines, Curtin University, Mining 3, Australia \\ I Onederra School of Mechanical and Mining Engineering, The University of Queensland, \\ Australia
}

\begin{abstract}
In Block Caving drawbells allow for flow of broken rock. The drawbell construction starts with a drawbell design, which is constrained by the extraction layout shape and development drives sizes. The resulting shape of the drawbell is highly influenced by drilling performance, particularly drillhole deviation. This paper presents the results of a comprehensive analysis of drillhole deviation data undertaken from more than 2,000 holes of $76 \mathrm{~mm}$ diameter, having an average length of $12 \mathrm{~m}$ and drilled in more than 500 ring positions. In terms of drawbell design, the analysis indicates that the holes less affected by drillhole deviation are those with plunge angle ranging between $65^{\circ}$ to $90^{\circ}$. Those holes are located near the centre of the drawbell. The holes less inclined show more deviation. They correspond to those forming the edge of the drawbell shape. Therefore, these areas can be exposed to possible blast damage due to confined charges. The analysis also indicated that 59\% of the measured points have a drillhole deviation percentage (DD\%) greater than $2 \%$, while $2 \%$ of the points present a DD\% over $10 \%$. An industry standard for drawbell drill deviation along drilled depth was developed as a tool to check the effectiveness of a blast design, in terms of drill patterns that are likely to appear due to drillhole deviation.
\end{abstract}

\section{Introduction}

A drawbell is a geometry acting as a funnel for broken rock, which allows for flow between a block caving undercut level, where the rock mass starts the process of breaking, and the production level. The current measure of achievement for the commission of a drawbell design is when rock material flows and drawpoints are used. However, the caving operation requires that the surrounding rock remains stable, from drawbell construction to all stages of cave production. As mine sites get deeper, production levels become unstable. The drilling of drawbells is one of the factors that can contribute to minimizing rock damage in the surrounding area of drawbells, improving the stability performance of the production level for block cave mines.

The drilling design of a drawbell is constrained due to a series of decisions. This includes the caving method variant, which defines the number of stages required to blast a drawbell. The three more common layouts are the Offset Herringbone Layout and El Teniente Layout (Figure 1) and the less used Henderson or Z Layout (Brown 2007). After the mine layout is chosen, other geometry restrictions are imposed by the sizes of the equipment, which also influences the final drilling of a drawbell. The geometry design of a drawbell must allow ore flow, which defines an angle of the funnel greater than $45^{\circ}$, to avoid stacked rock inside a drawbell (Brown 2007) and geometry parameters focused on draw interaction have been analysed by others (Castro 2006; Pierce 2010). This paper focuses on the analysis of the implemented drilling data, assuming that flow design conditions will work when the design is implemented correctly. 


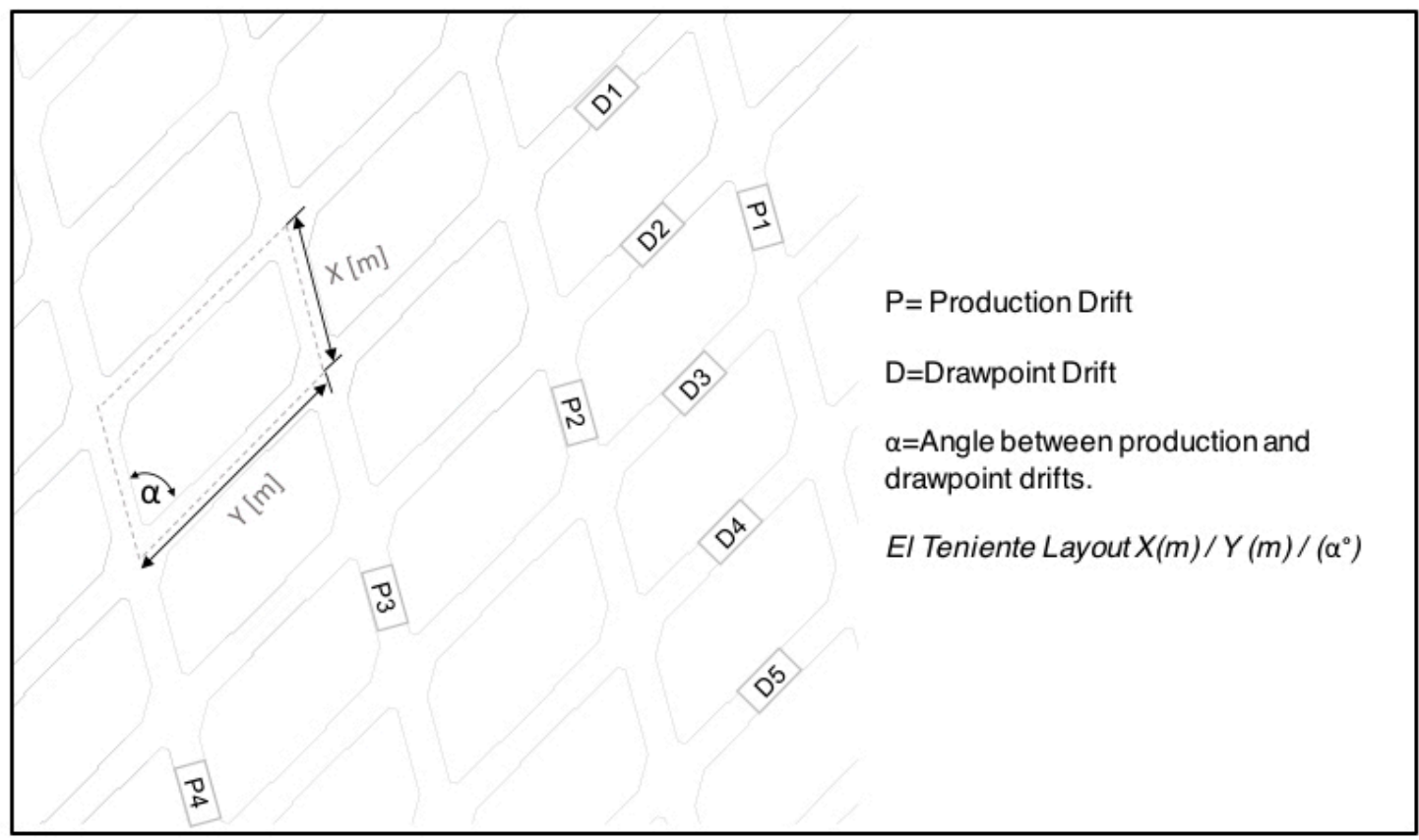

\section{Figure 1 Plan view of El Teniente layout}

\section{$2 \quad$ Methodology}

Data from the post-undercutting method (Brown 2007; Rojas et al. 2000) was available for this analysis (Figure 2 - left side). In this method, the drawbell geometry is created from the undercut and production levels using a drilling and blasting pattern of up holes that achieves the required geometry in two stages. The first stage creates a funnel in the production level, usually with a blast pattern around an up-hole raise acting as the initial slot (Figure 2-right side). The second stage creates a connection with the cavity using drilling and blasting fans from the undercut level (Brown 2007; Rojas et al. 2000)

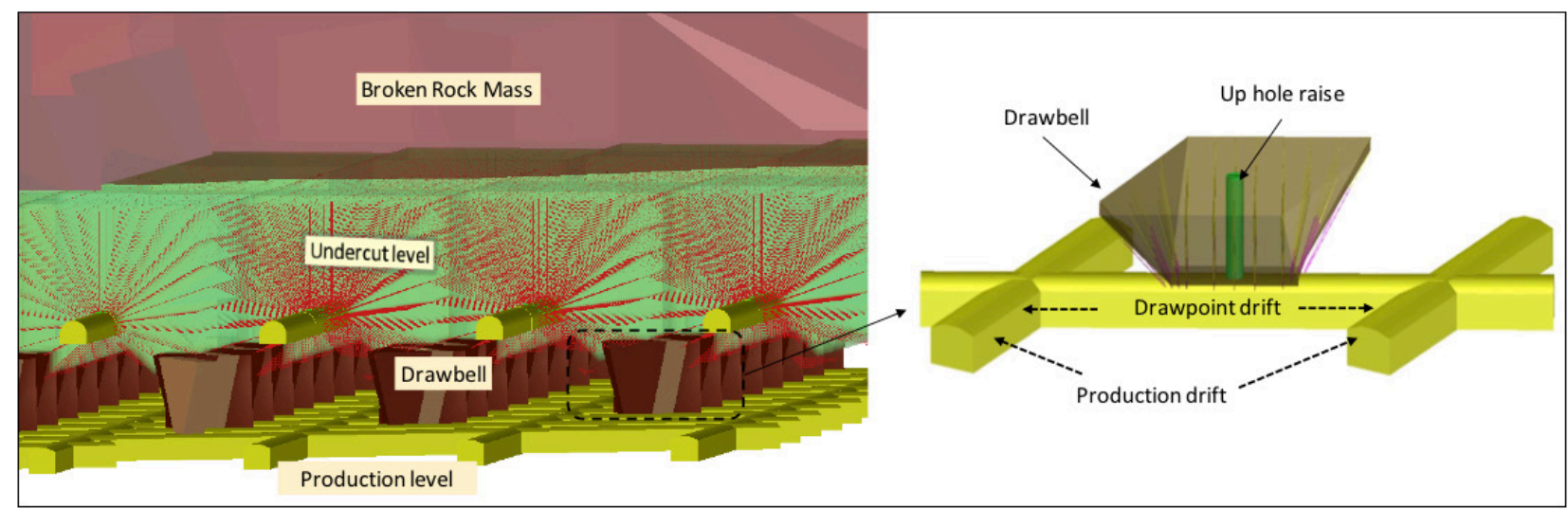

\section{Figure 2 Post-undercutting method and a detail of the first stage of the drawbell}

The pattern of drilling for the funnel part of the drawbell, depends on drillhole diameter, type of explosive and geotechnical conditions. Figure 3 shows the way that rings are typically allocated to build the drawbell geometry. The slot is formed by rings R1 and R2 plus 2 auxiliary rings. The two rings each side of the slot are drilled at $90^{\circ}$ and $80^{\circ}$ and are called Main Rings and finally two rings each side, inclined $70^{\circ}$ and $60^{\circ}$ were called Corner Rings (Figure 3, right-bottom side). In general, every hole has some plunge angle different to $90^{\circ}$. 


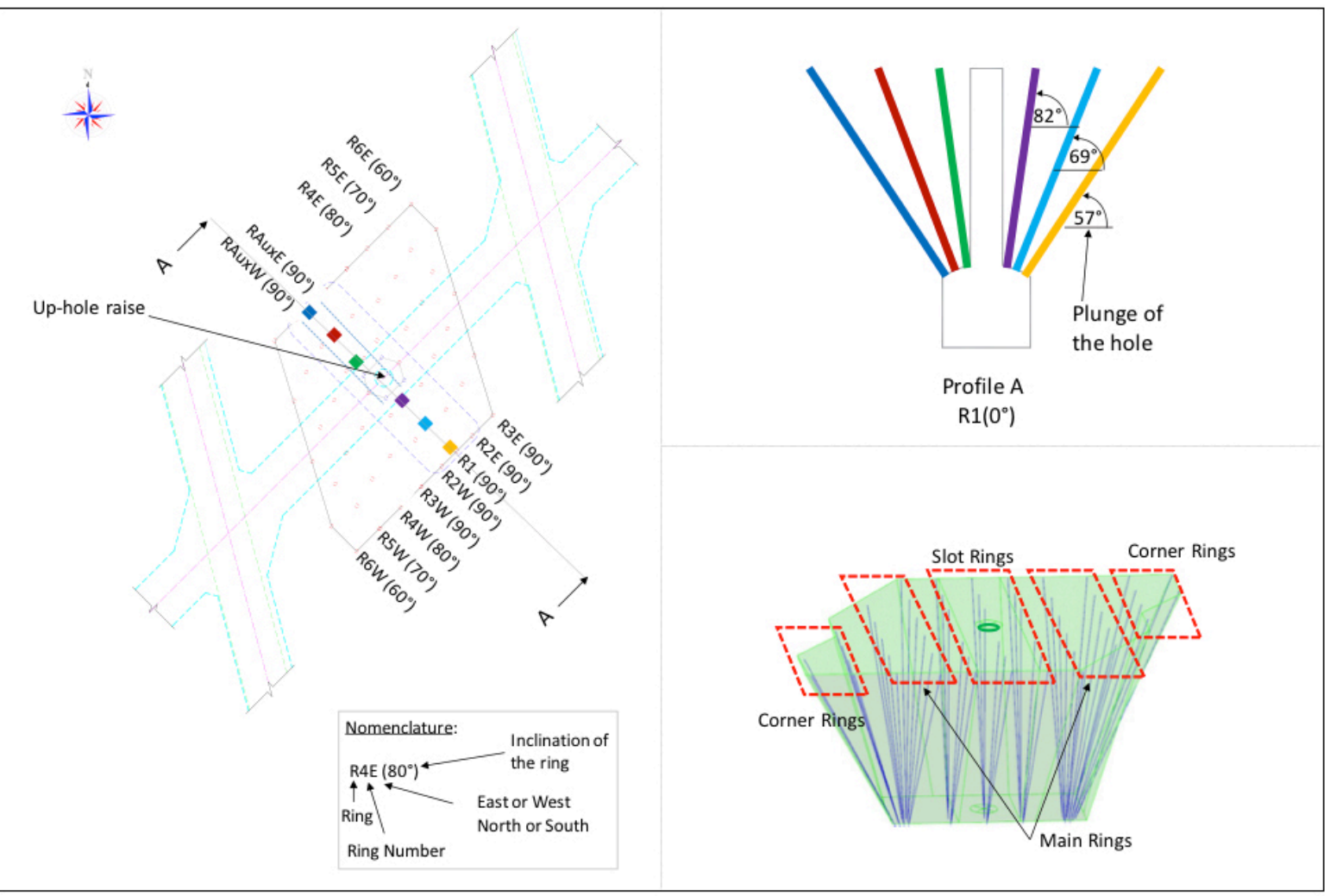

Figure 3 Typical drill pattern for drawbells analysed. Hole disposition and ring nomenclature

\subsection{Drillhole deviation analysis}

The most important parameter to characterize the quality of a hole drilled is the drillhole deviation. Drillhole deviation is a comparison between the actual and the designed hole. It can be calculated in different ways but generally expressed in meters or length percentage (Persson et al. 1994; Rostami \& Hambley 2011, Villaescusa 2014). Drillhole deviation is a sum of three different sources (Persson et al. 1994; Villaescusa 2014):

- Collaring deviation: inaccurate location of the initial drill position.

- Angular deviation: incorrect azimuth and/or plunge of the drill.

- Bending deviation: drill bit deviates from the straight path while the drilling is occurring.

A drawbell in a particular mine sector will be drilled according to a design that depends on the mining strategy, as it was discussed previously and is adapted for specific drift dimensions, lithology, and type of explosive (usually ANFO or Emulsion). The design is generally defined for a perfect drift shape, without over or under excavations and with no interference by cables or bolts plates used for ground support. In this research, drillhole deviation (DD) will be defined as a horizontal distance (in meters) between the point of measurement and its projection over a line that starts in the collar of the measured hole and has an azimuth and plunge that follows the design. Additionally, drillhole deviation percentage (DD\%) is defined as the proportion that DD represents in terms of the drilled depth (DH) in which it was measured. A detail explanation about how drillhole deviation was measured, in meters and as a percentage is presented in Figure 4. This definition of drillhole deviation allows to investigate the effects of angular and bending deviation. 


\subsubsection{Measurement}

The drillhole deviation data analysed here was measured by a probe called REFLEX EZ-AQ (REFLEX 2019). This electronic instrument measures azimuth and plunge of a hole. The probe is made of magnetic and gravitation sensors, as well as solid magnetometers and accelerometers with a factory precision of $\pm 0.35^{\circ}$. Collaring position is based on topographic measurements. The holes were cleaned before measurement and the length was measured. The device is introduced into the hole and the information is captured in an electronic unit that stores the information for download.

\begin{tabular}{|l|l|l|}
\hline Original & $\begin{array}{c}\text { Measurement of drillhole } \\
\text { deviation }\end{array}$ \\
\hline & $\begin{array}{l}\text { DD: Drillhole deviation }(\mathrm{m}) \\
\mathrm{DH} \text { : Drilled depth }(\mathrm{m}) \\
\mathrm{DD} \%: \text { Drillhole deviation } \\
\frac{100 \mathrm{DD}}{\mathrm{DH}}[\%] \\
\text { Designed Drawpoint drift } \\
\text { Measured points } \\
\text { Designed hole } \\
\text { Drilled hole } \\
\text { Relocated designed point }\end{array}$ \\
\hline
\end{tabular}

Figure 4 Drillhole deviation measurements, assuming the collaring deviation to be zero

\section{Database description}

The data analysed comes from El Teniente mine of CODELCO and involves four different mining areas detailed in Figure 5. The information corresponds to 40 different drawbells, with a total of 485 rings, 2,219 drilled holes (i.e. a total of 10,431 measurement points). Most of the data is from T45 rods with a $76 \mathrm{~mm}$ bit. Esmeralda, Pacifico Superior, and Reservas Norte sectors have samples located in red and light blue rock type units, while Dacita sector samples are from the blue unit. These units were classified in the base of the P32, number (Dershowitz \& Herda 1992; Hekmatnejad et al. 2017) classification that has been used in El Teniente mine to asses rock mass stability (Brzovic \& Villaescusa 2007; Brzovic et al. 2015). The calculations of P32 includes the effect of soft veins in the rock mass classification. Observations in terms of fragmentation indicate that the higher the value of P32, the easiest is for rock mass to propagate the fragmentation and the caving process (Brzovic \& Villaescusa 2007).

Reservas Norte and Dacita are the deepest sectors operating in El Teniente Mine. The current layout is $\mathrm{El}$ Teniente $34.6(\mathrm{~m}) / 20(\mathrm{~m}) / 60^{\circ}$ (Figure 6 - left column) and the direction of the production drifts is N30 $\mathrm{W}$. Esmeralda is a sector located on the east side of the mine, with a layout of El Teniente $34.6(\mathrm{~m}) / 24.5$ $(\mathrm{m}) / 60^{\circ}$ and the direction of the production drifts is $\mathrm{N} 30^{\circ} \mathrm{E}$, as can be seen in Figure 6 (central column). Pacifico superior sector is the shallowest active operation in El Teniente Mine. It is located on the west side of the mine and the production drifts have an east-west direction (Figure 6 - right column). 


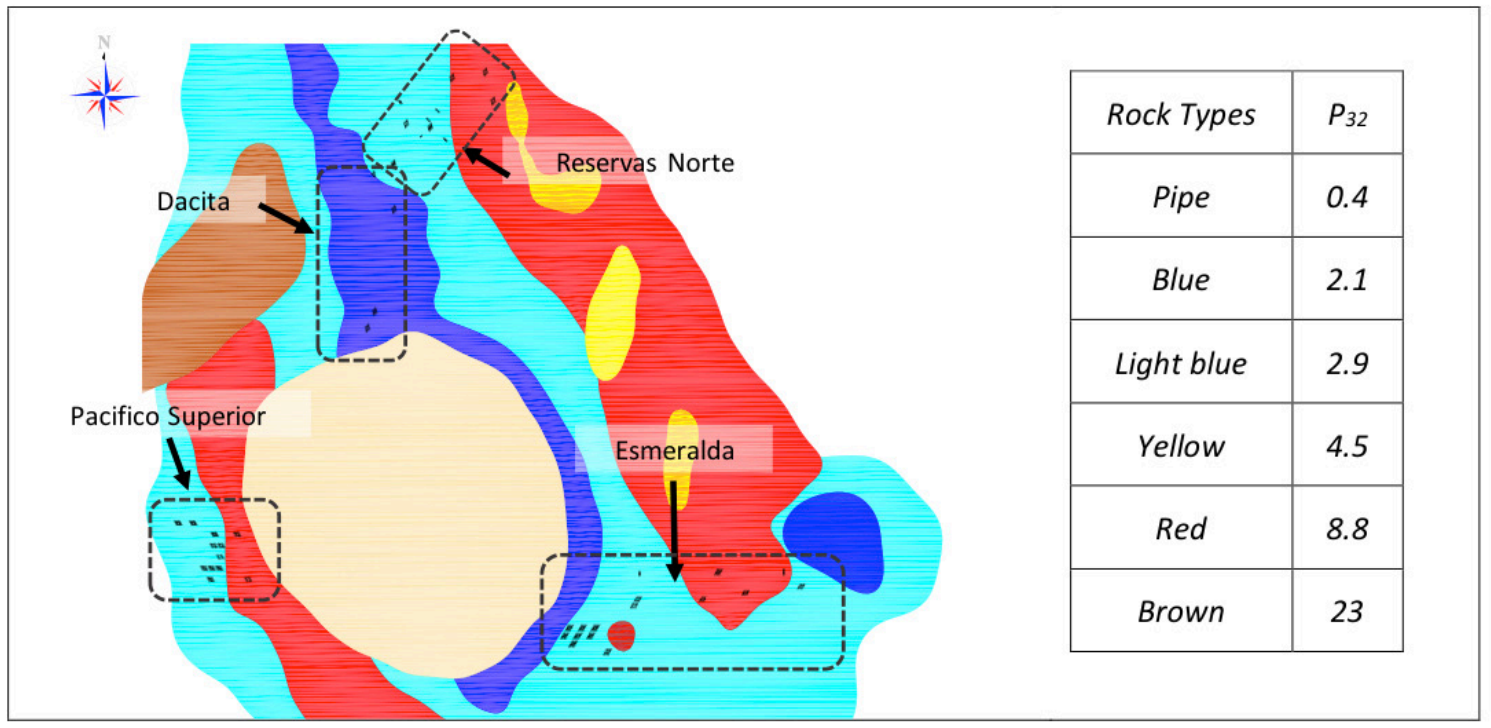

Figure 5 Mines and their geotechnical units inside El Teniente deposit

\begin{tabular}{|l|l|l|}
\hline $\begin{array}{c}\text { Reservas Norte and Dacita } \\
\text { Layout }\end{array}$ & Esmeralda Layout & Pacifico Superior Layout \\
\hline
\end{tabular}

Figure 6 Layout and drawbell direction description for each area analysed

\section{$4 \quad$ Results of analysis}

A general picture of drillhole deviation (DD) is presented in Figure 7. The figure shows is a scatter plot of the drillhole deviation values, which were plotted in the position $X$ and $Y$ of the measured points, and translated to the origin, following their relative location inside the drawbells. The drillhole deviation scale used is between 0 to $1.5 \mathrm{~m}$, which includes $99.8 \%$ of the data. The holes have an average length of 12 $\mathrm{m}$, which means that deviation can be up to $13 \%(1.5 \mathrm{~m})$. It can also be seen that the points farther from the origin coordinates are those with larger drillhole deviation, which suggests that inclination and/or length are the reason for this increase in deviation. 
Hole deviation distribution from a design target in North and East coordinates appears to be uniformly distributed (Figure 8). This figure shows the contour distribution for all the data measured, including the three different orientations showed in Figure 6. The contouring calculation was made using the surface mapping software called SURFER (Golden Software 2019), using the inverse distance weighted (IDW) method for gridding (Davis 1986). The average measured target $(0.1,-0.05)$ was very close to the target origin $(0,0)$.

The drillhole deviation distribution as a percentage of the drilled depth (DD\%) for all the points measured is shown in Figure 9. The blue bars in the figures are the number of points that have a certain DD\% indicated in $\mathrm{x}$-axis and the blue line with the red points is the cumulative percentage. It can be seen that $59 \%$ of the measured points have a DD\% greater than $2 \%$ and a $35 \%$ of the points have a DD\% over $3 \%$, while $2 \%$ of the points present a DD\% over $10 \%$.

Plunge hole deviation $\left(\triangle \mathrm{P}\left[^{\circ}\right]\right)$ was defined as a comparison between the plunge angle designed and the plunge angle measured. When the result is positive, the $\Delta \mathrm{P}\left[^{\circ}\right]$ could be influenced by the action of the gravity force. The calculations of the $\left.\Delta \mathrm{P}^{\circ}{ }^{\circ}\right]$ indicate that the majority of deviations $(61 \%)$ are positive however, the effect of gravity force is not the only factor explaining drillhole deviations.

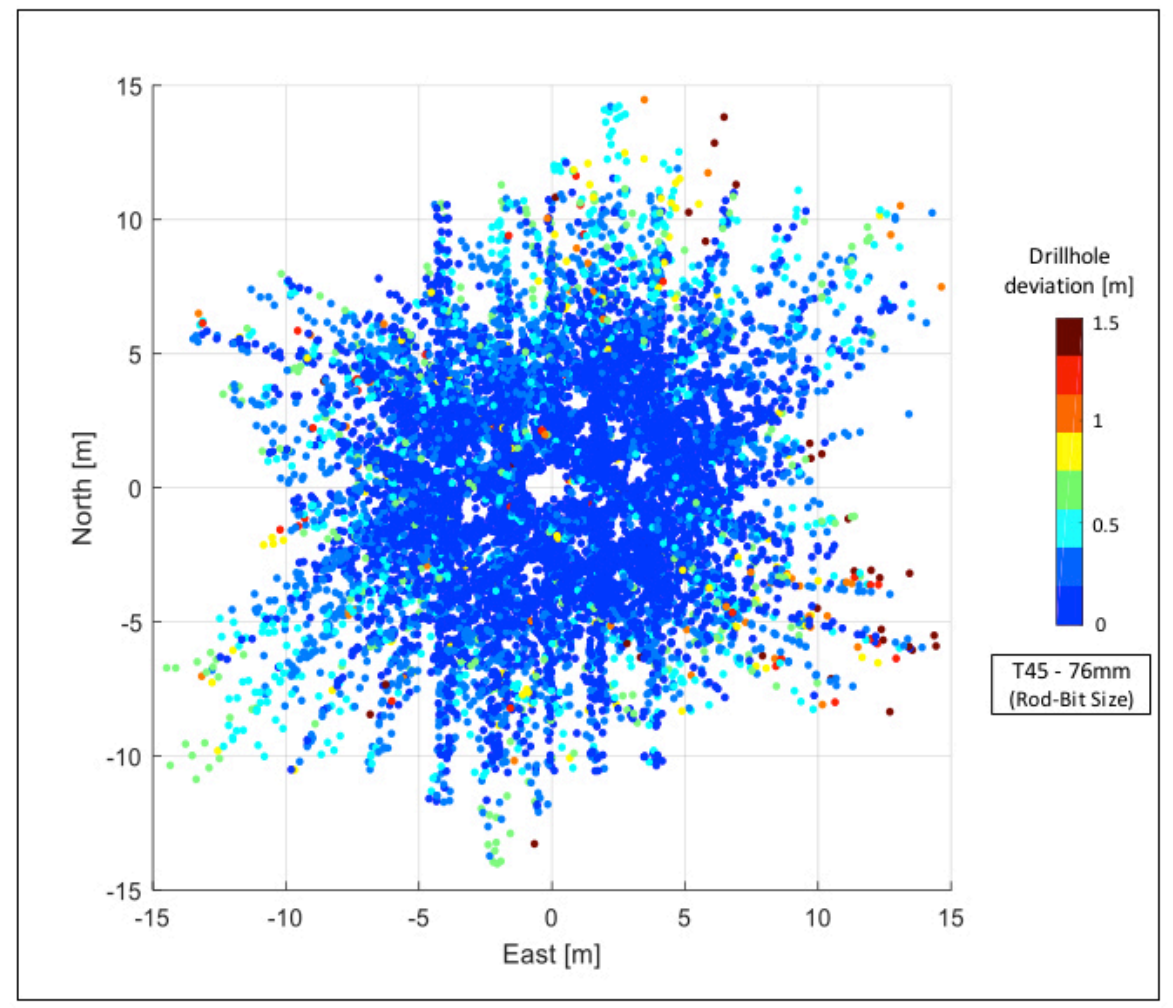

Figure 7 Drillhole deviation for each drawbell measured, data translated to origin coordinates 


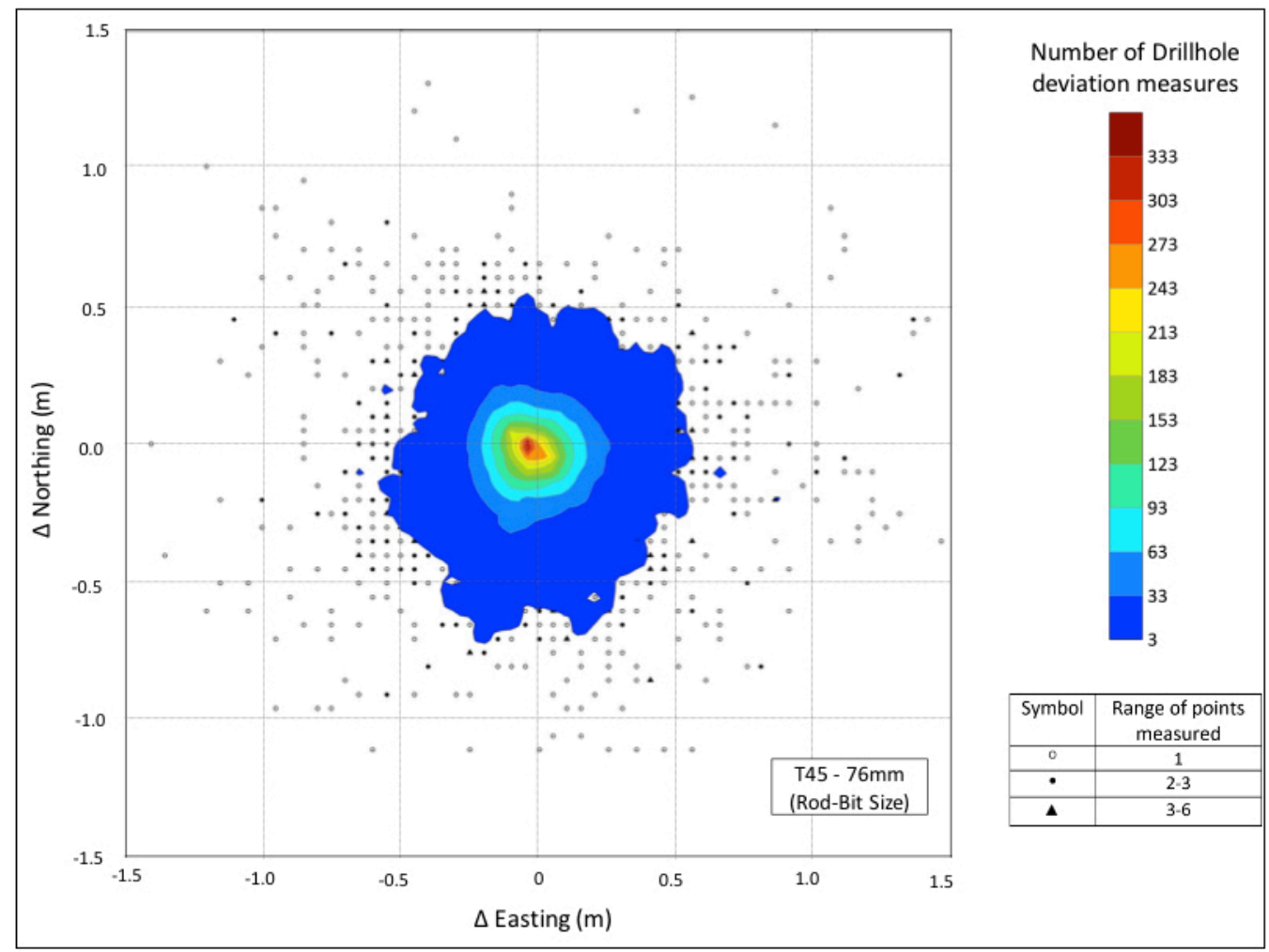

Figure 8 Entire drillhole dataset deviation distribution from the design target

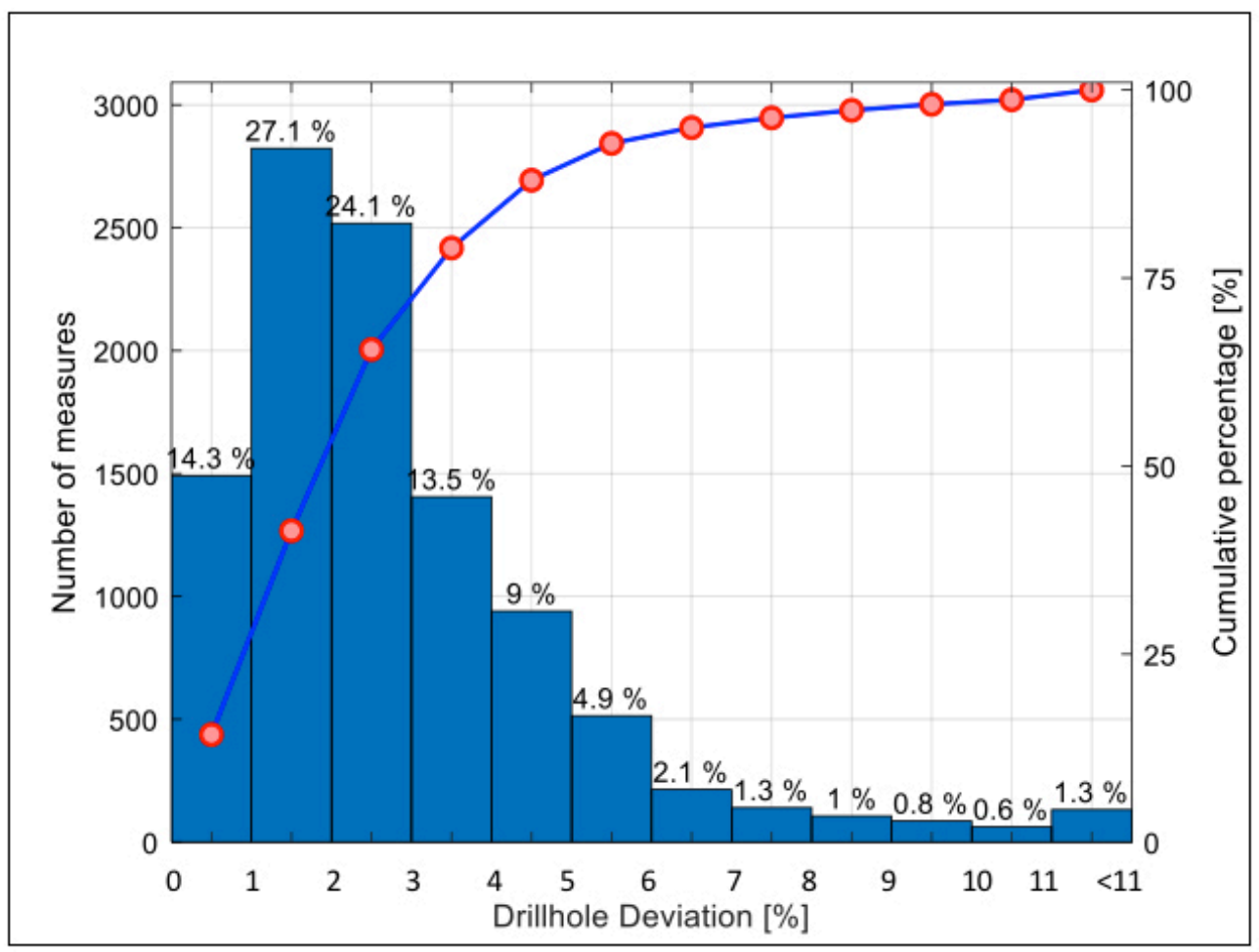

Figure 9 Drillhole deviation percentage (DD\%) distribution

\subsection{Parameter analysis}

\subsubsection{Drilled depth $[\mathrm{m}]$}

Drilling deviation (DD) is commonly analysed in terms of drilled depth (DH). In fact, one of the types of drillhole deviation is the bending deviation, which can be directly proportional to the drilled depth. Figure 10 presents the correlations between drilling deviation and drilled depth. The analysis of the figure 
indicates that drillhole deviation increase due to higher hole length $(m)$. Data dispersion in the figure is highly spread for all the range of drilled depth. The features of the data suggest that other analytical tool must be used and that a linear regression is not a good predictor for this data set, because the designs could be missing a significant amount of information.

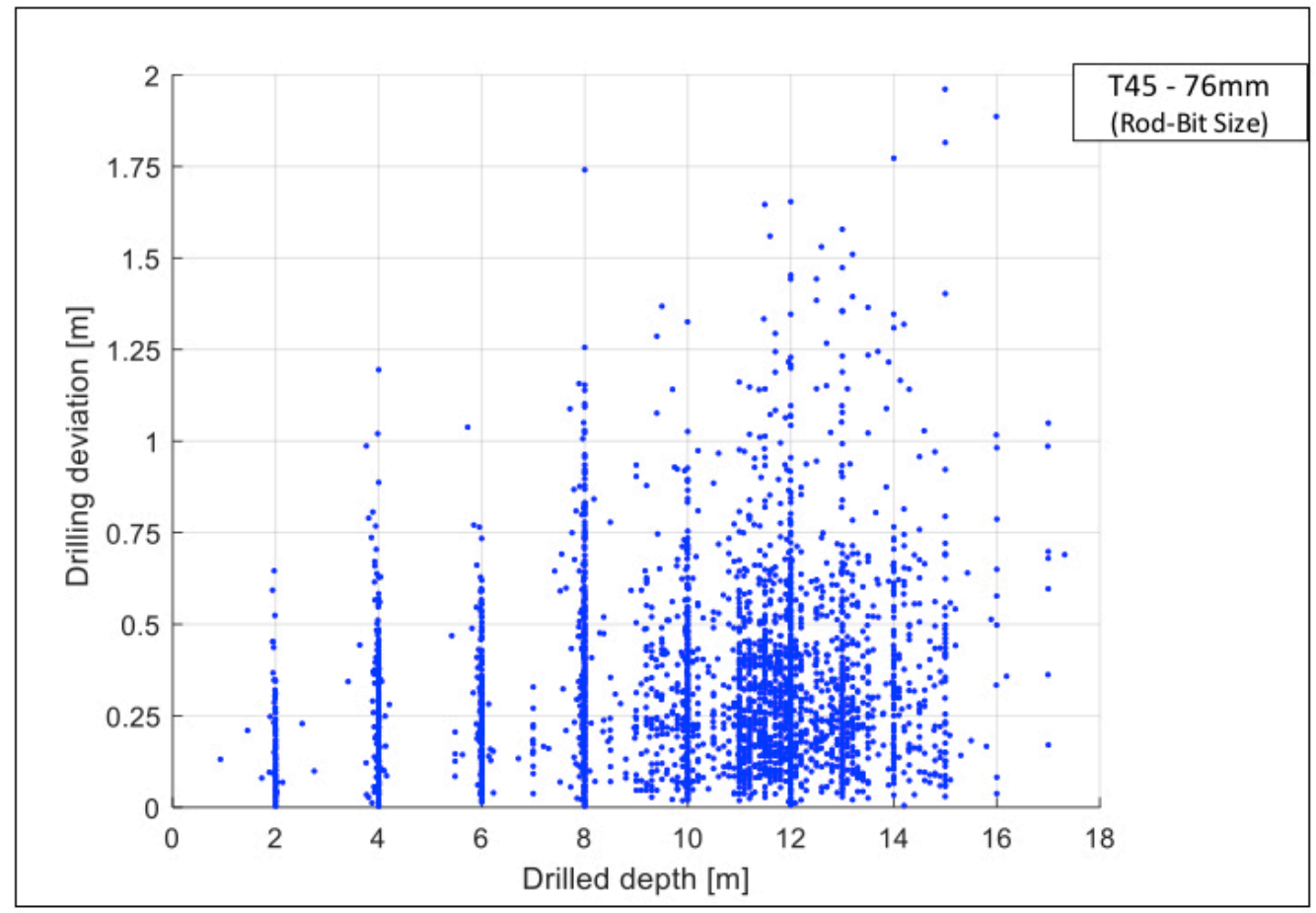

Figure 10 Drilling deviation versus drilled depth for all the measured points

A different type of analysis that can be used is the box plot (Heumann et al. 2016; Velleman et al. 2004). Figure 11 displays the data using the drillhole deviation separated by 8 ranges of drilled depth, both terms in equivalent blasthole diameters. In this case, the data can be interpreted more directly as bending deviation as a function of drilled depth increases. The data shows that each of the boxes is wider than the previous one. This increment in the dispersion could be attributed to bending deviation.

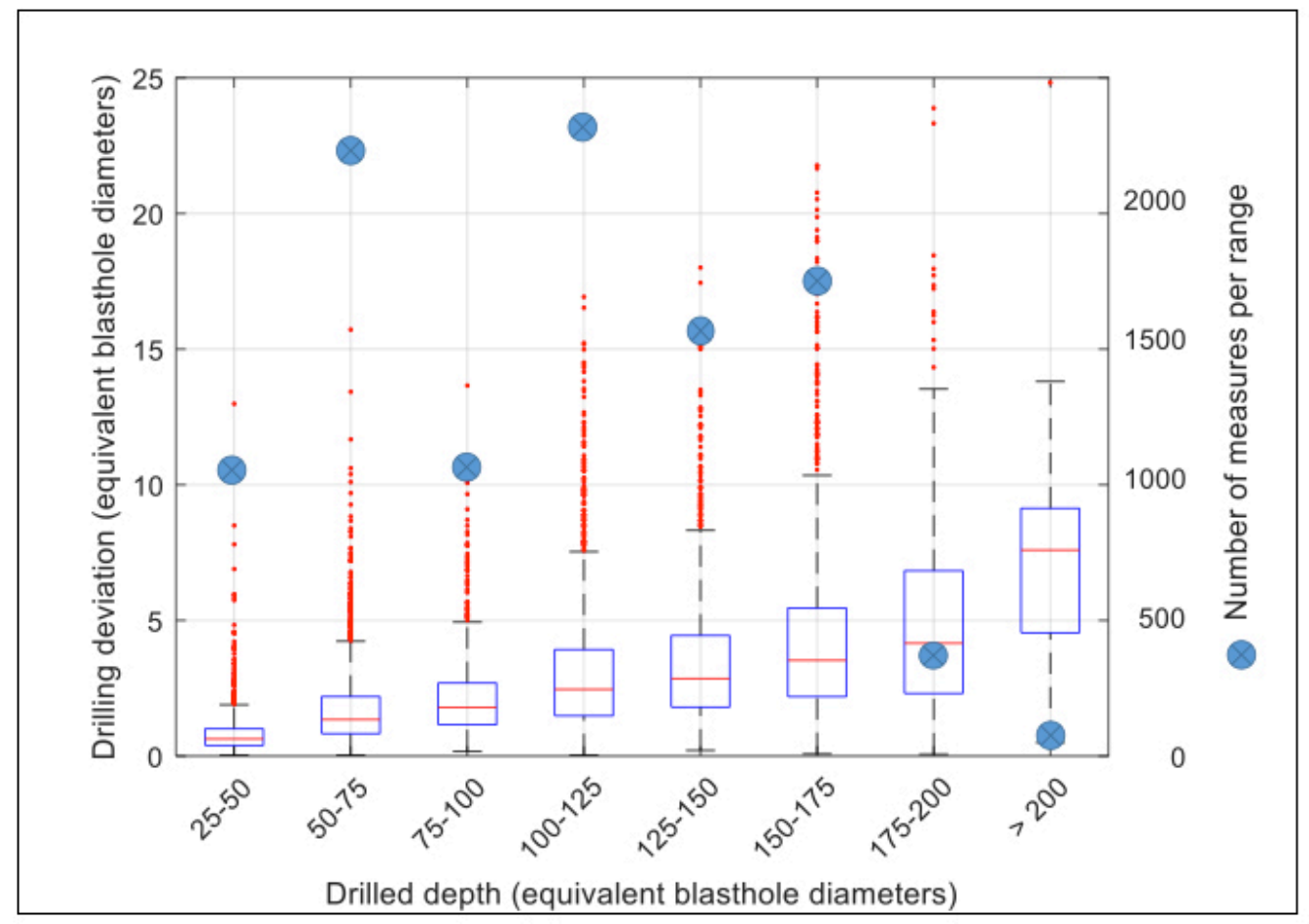

Figure 11 Boxplot of the drilling deviation and number of measures along drilled depth. Entire dataset displayed 
Another advantage of these graphs is that the amount of outliers is fixed in a small number, outside the whiskers. In the case of the data used, a total of $6 \%$ of the points were out of the upper whiskers and zero out the bottom whiskers. The number of outliers decreases in the last 2 ranges, because the amount of points measured is lower, as can be observed from the blue points of Figure 11.

In order to compare these results with published data from other mine site, an industry standard for the Canadian experience in longholes, which was presented by Heilig (1999), was studied (Figure 12). Drillhole deviation and drillhole depth were analysed in terms of equivalent blasthole diameters, which is the same information from Figure 10 but divided by $0.076 \mathrm{~m}$ (bit size). In this standard, collaring, angular and bending deviation areas are defined. A similar tool for the drilling of drawbells geometries offers practical uses in the design process. Specifically, it can be used as a tool to check the effectiveness of a blast design and to test different configurations of drill patterns that are likely to appear due to drillhole deviation.

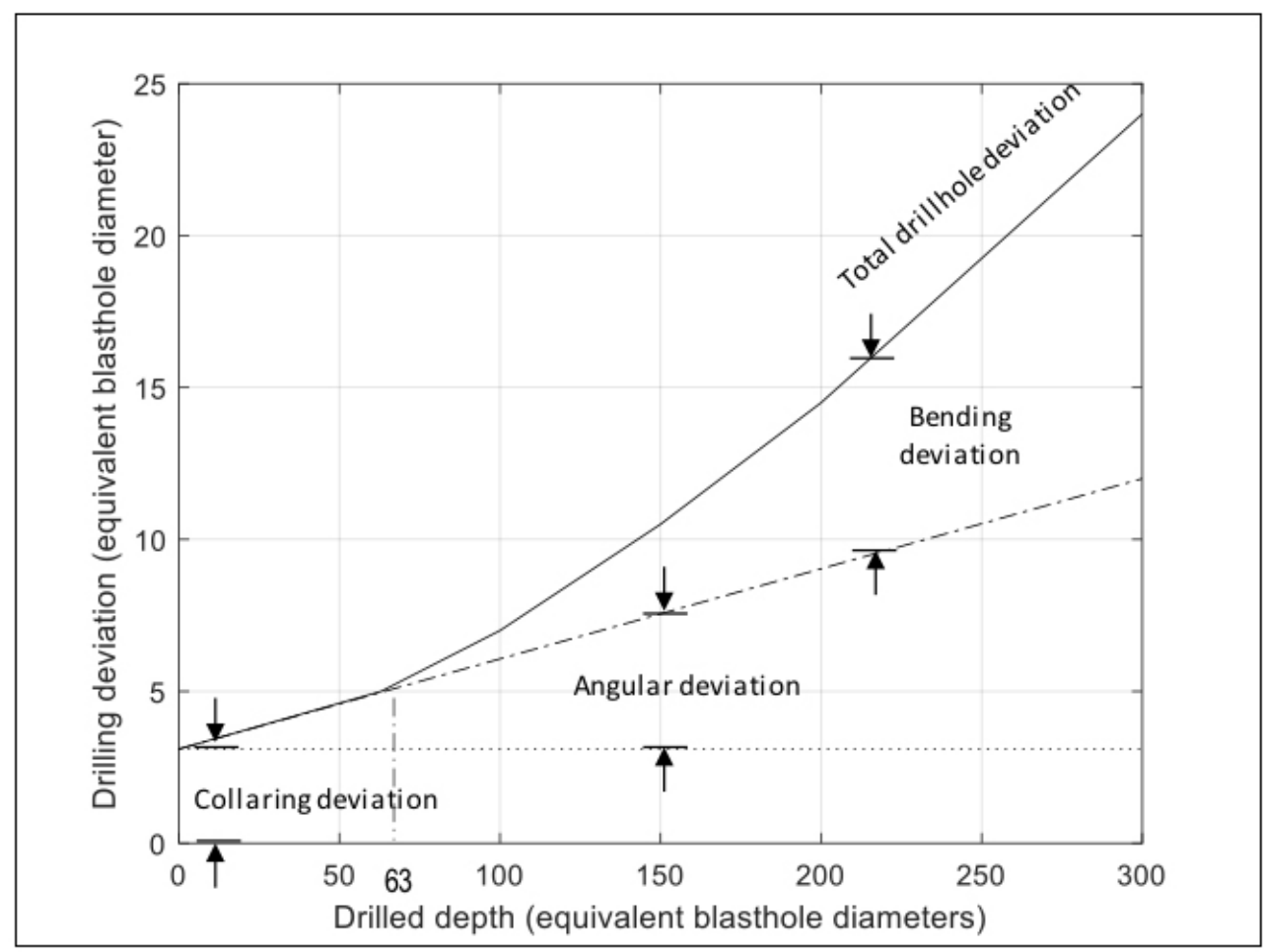

Figure 12 Drillhole deviation types in longhole drilling. (After Heilig (1999). Blast engineering - Course notes for the masters of engineering science in mining geomechanics. Western Australian School of Mines, Curtin University

Figure 13 shows a comparison between the information from box plot graph (Figure 11) plotted in blue lines and drillhole deviation types in longholes from Figure 12, plotted in black lines. The first line in blue is linear regression built across the red lines inside de boxes, which are the median values, in combination with the central value of the drilled depth in equivalent blasthole diameters of each box (i. e. 37.5, 62.5 , etc.). The polynomial Y1 was created from the top whisker values, using a fixing interception in zero. Additionally, a tangential line to $\mathrm{Y} 1$ between the origin and a drilled depth in equivalent blasthole diameters of 63 was drawn. This line replicates the separation between angular deviation from bending deviation showed in Heilig (1999).

The information from Heilig (1999), plotted in black lines, was translated to zero collaring deviation. This made possible to contrast this information with the drillhole deviation analysed in this research, which does not include collaring error due to the given definition (Section 2.2.1). The analysis shows that linear regression of median values from drawbell is very similar to the angular drillhole deviation from previously published experience from open stoping. However, the total deviation defined by Heilig (1999) represents less deviation than the curve $\mathrm{Y} 1$ defined by drawbells. 


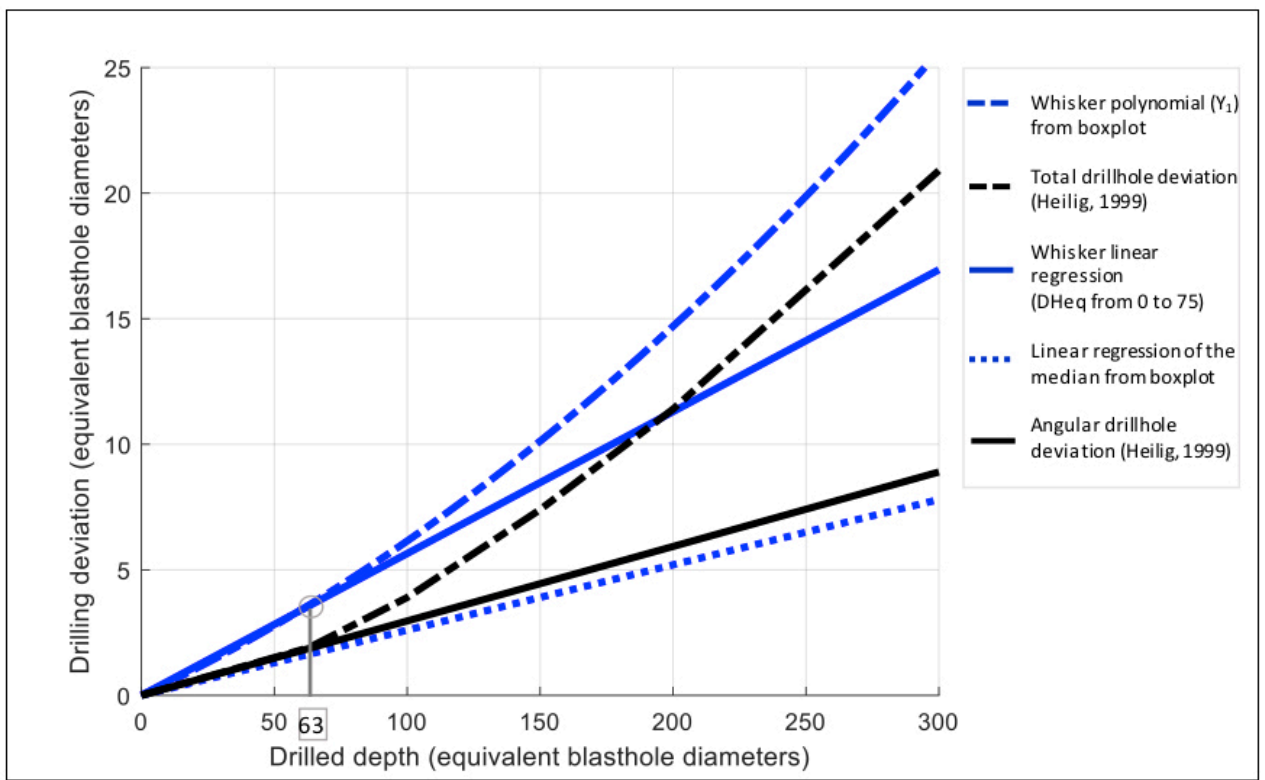

Figure 13 The construction of a standard curve for drillhole deviation in drawbells

Figure 14 shows a proposed model of drillhole deviation types for drawbells drilling. It is suggested as a standard for the drilling parameters of $76 \mathrm{~mm}$ bit size and T45 rods. This tool may also be used as an industry characterization of inclined/up-holes. The model of angular deviation proposed is the linear regression of the median values and the total deviation, including the bending deviation, is the whisker polynomial, both from boxplot (Figure 11). The tangential to the whisker polynomial between the origin and a drilled depth in equivalent blasthole diameters of 63 is defined as the range of angular deviation, parameter included due to the highly spread deviation.

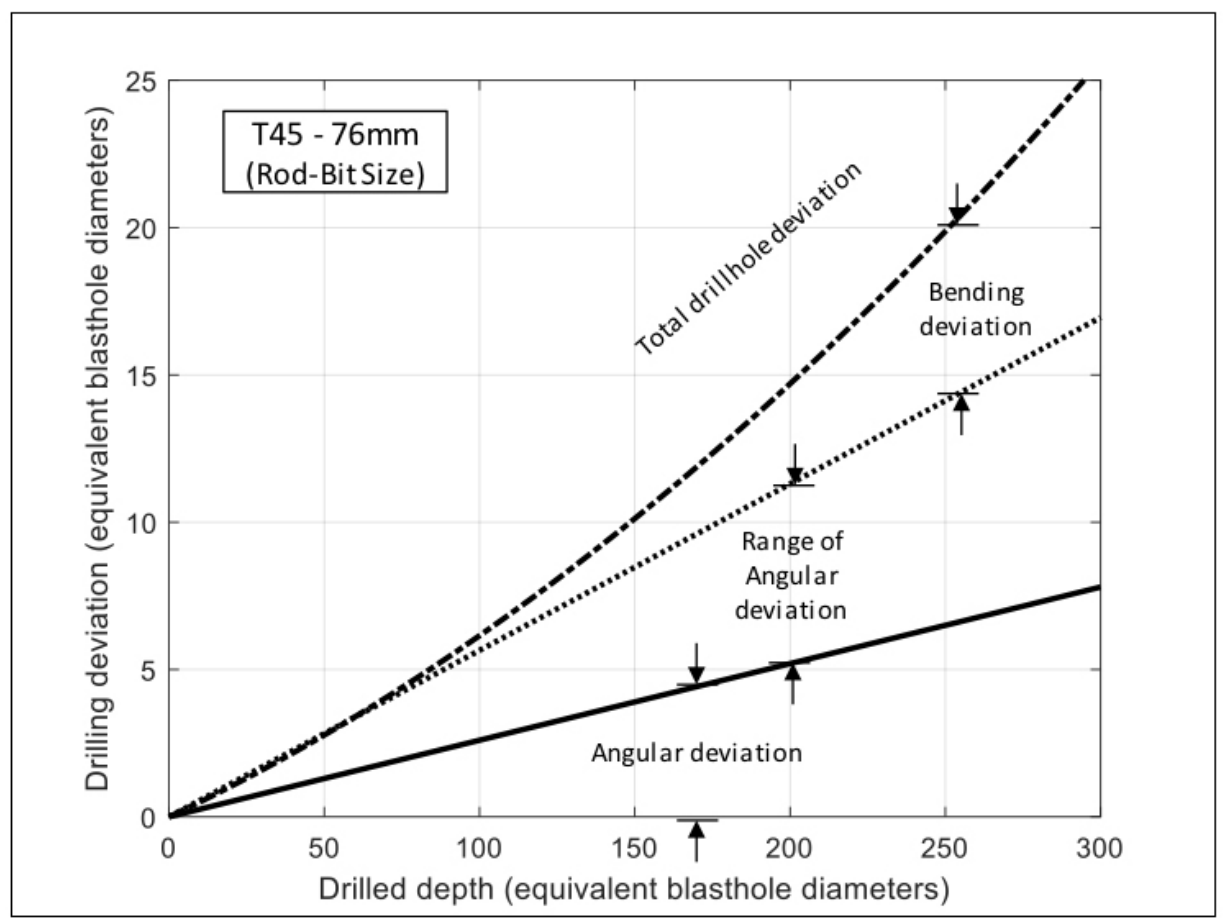

Figure 14 Proposed model of drillhole deviation types for drawbells drilling

\subsubsection{Hole plunge angle $\left[{ }^{\circ}\right]$}

One of the characteristics that make drawbells particularly complex geometries to be accurately drilled is the inclinations of the holes. The total inclination of the holes is the vector sum of the ring inclination (Figure 3) and the hole inclination (Figure 3, right-top side). The hole plunge angle, which is the total 
inclination, was plotted in Figure 15 in 9 ranges from $45^{\circ}$ to $90^{\circ}$. From the figure, it can be seen that drillhole deviation is greater for less inclined holes.

The inclination features can be spread in 3 ranges as design advice for drawbells in terms of risk. These can be defined as higher, medium and lower risk, as shown the $x$ axis of Figure 15 . The range and values indicate that avoiding inclinations under $65^{\circ}$ and especially under $50^{\circ}$ would improve the performance of the drilling results. The right axis of Figure 15 shows the number of points measured in each range. The drawbells analysed presented $60.2 \%$ of points drilled in lower risk and a $37.2 \%$ and $2.4 \%$ of points in a medium and higher risk plunge angle respectively. The holes that present a lower hole plunge angle are those that form the edge of the drawbell shapes, therefore, they are closer to the crown pillar and drifts in the undercut and production levels. Due to this higher deviation of the drillholes, these areas may be exposed to blast damage due to confined charges.

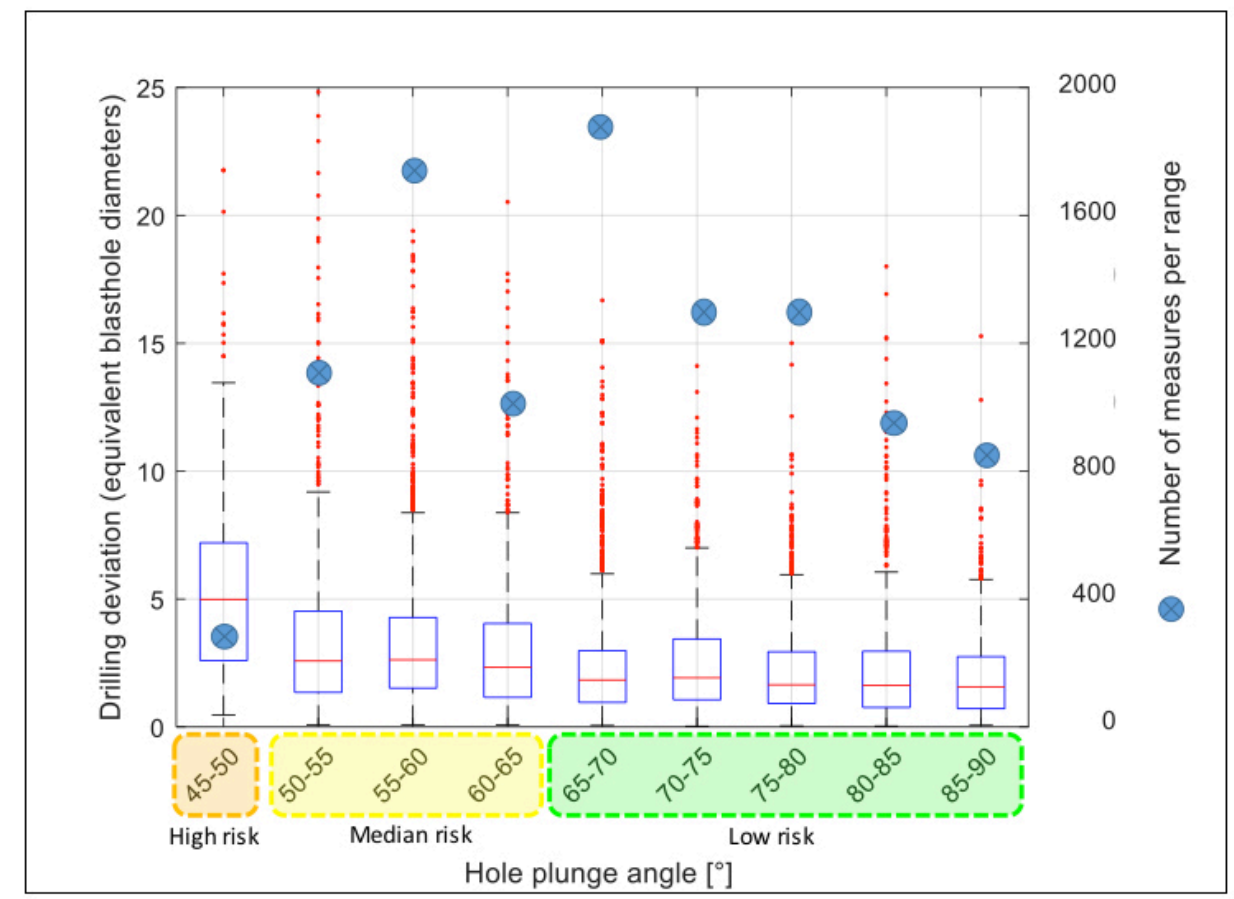

Figure 15 Boxplot of the drilling deviation and number of measures along hole plunge angle. Entire dataset displayed

\subsubsection{Toe position}

The toe position of a hole is defined as the last point measured in each hole. The total number of toe position/holes studied was 2,219. The average of drillhole deviation found was $0.33 \mathrm{~m}$, which is $3 \%$ of deviation in a hole of $12 \mathrm{~m}$ (average of hole length).

In order to characterize this parameter, the burden tolerance value was also investigated. In drawbell geometries, a burden is a variable number having a maximum value in the toe position. Hamrin (Hamrin 1993) proposed a limit for the total deviation of half of the burden (B/2) to define the maximum hole length for longhole blasting in Sublevel Caving. This recommendation is valid for open stoping geometries, which are less confined geometries than drawbells. Therefore, a quarter of the burden (B/4) was also studied as a tolerance value, considering the hypothetical case when two holes that were consecutively blasted.

Burden is a value that depends on the hole detonation timing. Drawbells are usually blasted using a circular pattern, thus a representative value of $2.2 \mathrm{~m}$ was analysed. Therefore, the number of holes exceeding the value of $B / 2(1.1 \mathrm{~m})$ was $2 \%$ and the number of holes exceeding $B / 4(0.55 \mathrm{~m})$ was $15 \%$. 
A contouring of the top of the drawbells per mine is shown in Figure 16. Inside each contouring, the edge of the slot shape was outlined using a broken red line. The analysis shows that most of the drillhole deviation is concentrated in the drawbell corners and in the drawbell's edge.

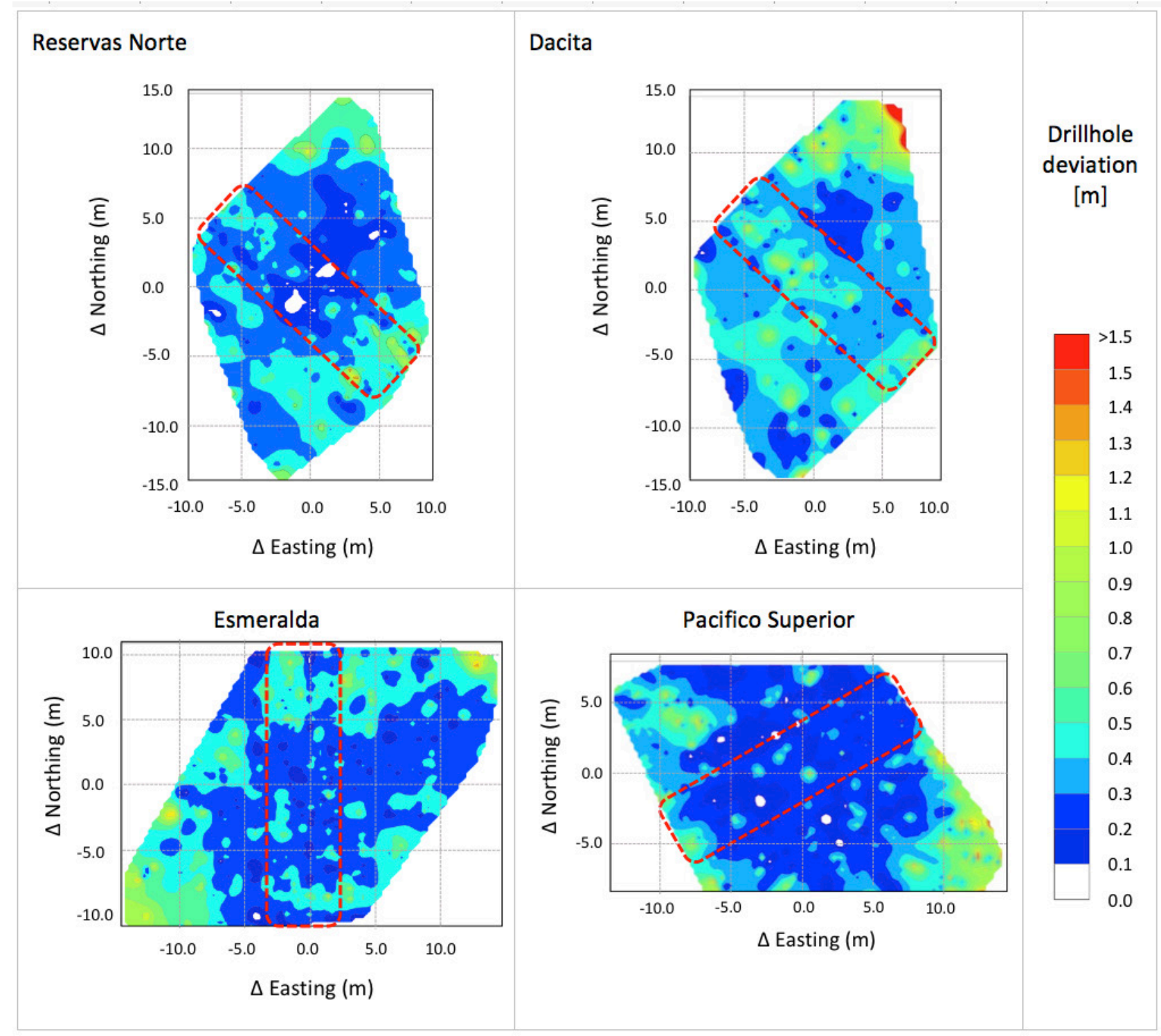

Figure 16 Contouring of drillhole deviation in the top face of the drilled drawbells (toe position). Entire dataset displayed per sector

\subsubsection{Ring location inside a drawbell}

Ring positions were divided into 3 parts, slot rings, which are the 3 rings in the slot position, 2 rings each side of the slot of the drawbell called main rings and two rings located further away with respect to the central raise, called corner rings. A plan view of the definition was presented earlier in Figure 3.

The design of the slot rings consists of 3 rings plus 2 auxiliary rings close to the central up-hole raise, with all rings inclined at $90^{\circ}$. The number of holes measured was 943 , representing a $42 \%$ of the total of holes measured. The drillhole deviation average for the toe position was $0.29 \mathrm{~m}$ with an STD of 0.21 $\mathrm{m}$. The main rings are generally 2 rings each side, inclined from $80^{\circ}$ to $90^{\circ}$. These holes represent a $39 \%$ of the total ( 865 holes), with a drillhole deviation average of $0.32 \mathrm{~m}$ (STD $0.25 \mathrm{~m}$ ) for toe positions. Finally, the corner rings presents 2 rings each side of the drawbell. These rings are the less inclined of the drawbell, with approximately $60^{\circ}$ and $70^{\circ}$ respectively (Figure 3). The number of rings measured was 411 representing $19 \%$ of the total points measured. The drillhole deviation average in the toe position was $0.44 \mathrm{~m}$ with an STD of $0.38 \mathrm{~m}$. 
Box plot for the parameters drilled depth and hole plunge angle were calculated and spread in the 3 rings samples. This information was summarized in Figure 17, showing the whisker and median of each of the ranges in 2 separate graphs. The left side of the figure, which corresponds to drilled depth, the whisker and median show an increment of drillhole deviation in equivalent blasthole diameters from slot to corner rings. The right image, which corresponds to the hole plunge angle shows the same trend, drillhole deviation is bigger for corner rings, followed by main rings and lastly slot rings, which suggest that an inclination lower than $90^{\circ}$ for ring negatively affects the performance of the drilling.

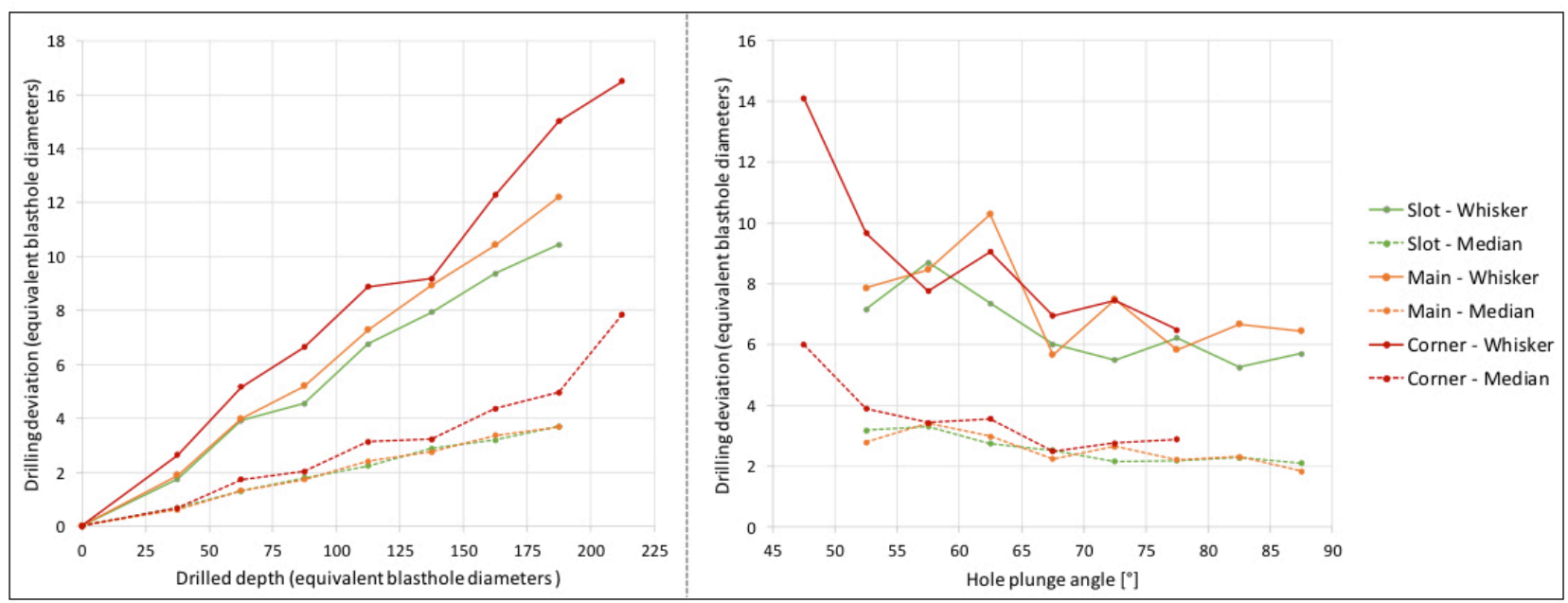

Figure 17 Summary of whisker and median parameters for slot, Main and Corner samples per ring location. From left to right: drilled depth $(\mathrm{m})$, hole plunge angle $\left(^{\circ}\right)$

\section{Conclusions}

A methodology for the statistical analysis of large databases of drillhole measures was described in this paper. The calculations of drillhole deviation contemplated 2 types of deviation, angular (incorrect drilling angle) and bending (deviation from a straight path). The collaring deviation was disregarded in the calculations. The longer the depth of measurements, the greater the measured deviation. Deviation values of up to $13 \%$ were calculated.

An industry standard developed by Heilig (1999) was used as a tool to propose a model of drillhole deviation types for drawbell drilling and to compare the drawbell data with the information from long holes. The dataset was prepared using box plots graphs. The analysis showed that the median values from the boxplots were similar to the angular deviation of long holes in sublevel open stoping. Bending deviation was obtained from a polynomial regression of the top whisker points. The total deviation proposed for drawbells represents more deviation than the presented by Heilig (1999).

Drillhole deviation (DD) is greater for less inclined holes. Drillhole deviation (DD) is greater for less inclined holes. A range of hole inclination angles was proposed, suggesting designs with more than $65^{\circ}$ of total inclination (median risk of large DD). It is also suggested to avoid inclination angles lower than $50^{\circ}$ (high risk of large DD). The holes that present lower inclination are those located in the edge of drawbell, leaving the production level of the mine exposed to possible blast damage due to confined charges. The same effect is seen in terms of ring location, the analysis indicates that the rings less inclined, with longest holes within the drawbell shapes, are more affected by drillhole deviation, hence the external shape is exposed to the negative effects of drillhole deviation. The results indicate that a change in the designed shape will be required to control the rock mass damage in the surrounding area of the drawbells.

\section{Acknowledgement}

The authors acknowledge El Teniente Division, CODELCO Chile, for authorisation to publish this paper. The financial support of Becas Chile (CONICYT) and the WA School of mines is gratefully acknowledged. 


\section{References}

Brown, ET 2007, 'Block caving geomechanics', Indooroopilly, Qld., Julius Kruttschnitt Mineral Research Centre, The University of Queensland.

Brzovic, A, Rogers, S, Webb, G, Hurtado, JP, Marin, N, Schachter P, Alvarez J \& Barahona, K 2015. 'Discrete fracture network modelling to quantify rock mass pre-conditioning at the El Teniente Mine', Chile. Mining Technology, vol 124, pp. 163177.

Brzovic, A, \& Villaescusa, E 2007, 'Rock mass characterization and assessment of block-forming geological discontinuities during caving of primary copper ore at the El Teniente mine, Chile', International Journal of Rock Mechanics and Mining Sciences, vol 44, pp. 565-583.

Castro, R 2006, 'Study of the Mechanisms of Gravity Flow for Block Caving', Doctor of Philosophy, University of Queensland.

Davis, JC 1986, 'Statistics and data analysis in geology' (2nd ed.), New York: New York : Wiley.

Dershowitz WS \& Herda HH, 'Interpretation of fracture spacing and intensity', In: J.R. Tillerson, WR, ed. Proceedings of the 33th U.S. Symposium on Rock Mechanics, 1992 A.A. Balkema, Rotterdam

Golden Software, L 2019, Surfer. Golden, Colorado.

Hamrim, H 1993 'Precision drilling extends the range of long hole blasting', In: Almgren, G, Kumar, U \& Vagenas, N, eds. Second International Symposium on Mine Mechanization and Automation, 7-10 June 1993 Luleå, Sweden Rotterdam, the Netherlands. A.A. Balkema, pp. 143-151.

Heilig, J 1999, 'Blast engineering' - Course notes for the masters of engineering science in mining geomechanics. Kalgoorlie, Western Australia, Australia: Western Australian School of Mines, Curtin University.

Hekmatnejad, A, Emery, X, Brzovic, A, Schachter, P \& Vallejos, JA 2017, 'Spatial modeling of discontinuity intensity from borehole observations at El Teniente mine, Chile', Engineering Geology, vol 228, pp. 97-106.

Heumann, C, Schomaker, M \& Shalabh 2016, 'Introduction to Statistics and Data Analysis', Switzerland, Springer International Publishing AG.

Persson, PA, Holmberg, R \& Lee, J 1994, 'Rock blasting and explosives engineering', Boca Raton, Florida, CRC Press.

Pierce, M 2010, 'A model for gravity flow of fragmented rock in block caving mines'. Doctor of Philosophy, University of Queensland.

REFLEX, T 2019, 'The End-to-end Solution for Downhole Navigation', Available from: <https://reflexnow.com/solutions/ downhole-navigation>/ [11-09-2019].

Rojas, E, Molina, R, Bonani, A \& Constanzo, H 2000, 'The Pre-Undercut Caving Method at the El Teniente Mine, Codelco Chile', In: G, C. (ed.) Proceedings MassMin 2000, Brisbane: Australasian Institute of Mining and Metallurgy: Melbourne.

Rostami, J \& Hambley, D 2011, '7.2 Blasthole Drilling'. In: DARLING, P. (ed.) SME Mining Engineering Handbook (3rd Edition), Society for Mining, Metallurgy, and Exploration (SME).

Velleman, P, Hoaglin, D \& Harvard, U 2004, 'Applications, basics, and computing of exploratory data analysis', Ithaca, N.Y. , The Internet-First University Press.

Villaescusa, E 2014, 'Geotechnical Design for Sublevel Open Stoping', Taylor \& Francis. 